\title{
Self-emulsifying drug delivery formulations
}

Tarek M. Ibrahim ${ }^{\mathrm{a}}$, Marwa H. Abdallah ${ }^{\mathrm{a}, \mathrm{b}}$, Nagia A. El-Megrab ${ }^{\mathrm{a}}$ and Hanan M. El-Nahas ${ }^{\mathrm{a}}$

a Department of Pharmaceutics and Industrial Pharmacy, Faculty of Pharmacy, Zagazig University, Zagazig, Egypt.

${ }^{\mathrm{b}}$ Department of Pharmaceutics, College of Pharmacy, Hail University, Hail, Kingdom of Saudi Arabia.

Corresponding author e-mail: tarekmetwally333@gmail.com

\begin{abstract}
As a consequence of modern drug discovery techniques, lipid-based drug delivery systems are the most popular approaches usually used to improve the dissolution and oral bioavailability of hydrophobic drugs. Self-emulsifying drug delivery systems (SEDDS), as one class of these lipidbased systems, are isotropic mixtures of oil, surfactants and co-surfactants where the drug is usually better soluble than in oil alone. The principal characteristic of SEDDS is their ability to form fine oil in water micro-emulsifying drug delivery systems (MEDDS) upon dilution by an aqueous phase through the gastrointestinal tract. SEDDS are considered promising strategy to improve the rate and extent of oral absorption of drugs. However conventional liquid SEDDS have some limitations, solid SEDDS are prepared by solidification of liquid self-emulsifying ingredients into powders or nanoparticles. This overview gives a particular emphasis on the solidification techniques and applications of liquid SEDDS in the pharmaceutical dosage forms to meet a wide range of the formulation requirements achieving reasonable routes of administration with efficient oral bioavailability.
\end{abstract}

Keywords: Lipid-based, self-emulsifying, solidification, phase diagram

\section{INTRODUCTION}

Low oral bioavailability of drugs as a consequence of their low water solubility is a growing challenge to the development of new pharmaceutical products. One of the most popular approaches of oral bioavailability and solubility enhancement is the utilization of lipid-based drug delivery systems. Their use in product development is growing due to the versatility of pharmaceutical lipid excipients and drug formulations, and their compatibility with liquid, semi-solid and solid dosage forms (Cerpnjak et al., 2013).

In fact, the most popular approach is the incorporation of the drug compound into inert lipid vehicles such as oils, surfactant dispersions (Nielsen et al., 2008), selfemulsifying formulations (Balata et al., 2016), microemulsions (Okur et al., 2017), liposomes (Bulbake al., 2017), niosomes
(Ravalika and Sailaja, 2017), ethosomes (Bodade et al., 2013) and solid lipid nanoparticles (Stella et al., 2018) with particular emphasis on self-emulsifying drug delivery systems (SEDDS).

Self-emulsifying drug delivery systems (SEDDS) are thermodynamically stable, isotropically clear dispersions of oils stabilized by an interfacial film of surfactant molecules. The surfactant may be pure or combined with other additives such as cosurfactants. One characteristic of these systems is their ability to form fine oil-inwater $(\mathrm{O} / \mathrm{W})$ micro-emulsifying drug delivery systems (MEDDS) upon mild agitation when exposed to aqueous media (Figure 1). In addition, these systems are recently being used for improving the dissolution and absorption of lipophilic drugs (Porter et al., 2008; Cho et al., 2016). 


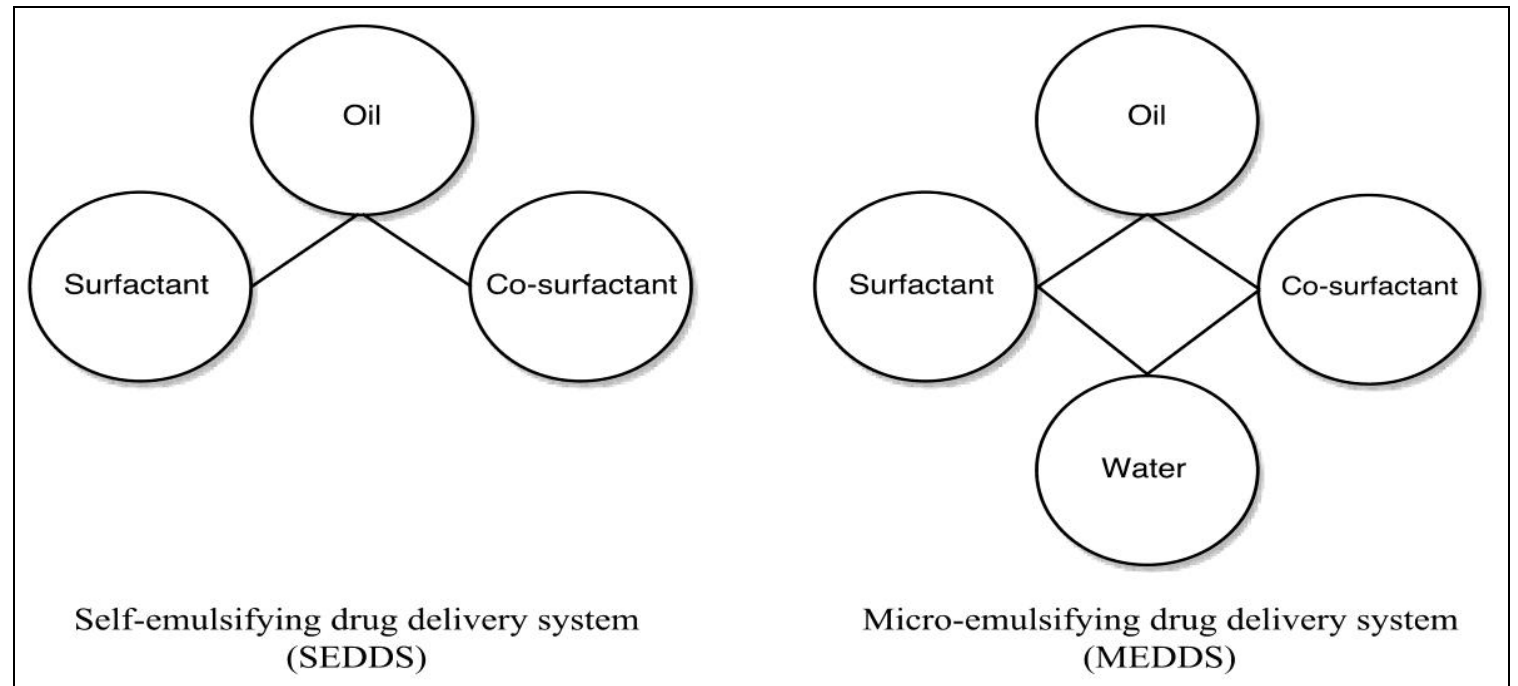

Figure (1): Schematic diagram of SEDDS and MEDDS

Self-emulsifying drug delivery systems, as an approach to improve the bioavailability of drugs, have many advantages such as:

- Where, hydrophobic drugs can often be dissolved in SEDDS allowing them to be encapsulated as unit dosage forms for peroral administration (Pouton, 2000).

- When such a formulation is released into the lumen of gastrointestinal tract (GIT), it disperses to form a fine emulsion of small droplet size $(<5 \mu \mathrm{m})$ with the aid of gastrointestinal (GI) fluids. This leads to in-situ solubilization of the drug that can subsequently be absorbed by lymphatic pathways, bypassing the hepatic first pass metabolism (Kohli et al., 2010).

- For drugs subject to dissolution ratelimited absorption, SEDDSs may offer an improvement in both rate and extent of the drug absorption and the reproducibility of plasma concentration profiles (Gershanik et al., 2000).

Self-emulsifying formulations are normally prepared as liquids that produce some limitations such as:

- Chemical instabilities of drugs and high surfactant concentrations in formulations (approximately 30-60\%) which may irritate the GIT (Gursoy and Benita, 2004).

- In-vitro/in-vivo correlations and therefore the lipid-based formulation needs to be developed and tested invivo in a suitable animal model (Porter and Charman, 2001).

- The precipitation tendency of drugs as a result of the dilution effect of the hydrophilic solvent (Kaukonen et al., 2004).

- Large doses, high production costs, low drug loading, few choices of dosage forms and difficulty in handling and portability (Czajkowska-Kosnik et al., 2015).

To address these problems, solid SEDDS have been investigated as an alternative approach. These solid systems require the solidification of liquid self-emulsifying (SE) ingredients into powders or nanoparticles which can be converted to various solid dosage forms. Thus, solid SEDDS have combined advantages of liquid SEDDS with those of solid dosage forms such as economical production, convenience of process control and higher stability, reproducibility and patient compliance (Czajkowska-Kosnik et al., 2015). 
Zagazig J. Pharm. Sci. June, 2018

Vol. 27, Issue 1, pp. 1- 21

\section{Components of SEDDS}

Gursoy and Benita, 2004 reported that self-emulsification has been shown to be specific to: the nature of the oil-surfactant pair, the surfactant concentration, oilsurfactant ratio and the temperature at which self-emulsification occurs. Detailed list of the most popular excipients used in the SEDDS preparation for oral administration has been illustrated by Hauss, 2007 as follows:

1. Drug candidates
ISSN 1110-5089

ISSN (on-line) 2356_9786

The use of SEDDS can be extended to solve the problems of all four drug categories of Biopharmaceutical Classification System (BCS) (Table 1) (Kawabata et al., 2011) especially class II drugs such as Coenzyme Q10 (Kommuru et al., 2001), Halofantrine (Holm et al., 2003), Ramipril (Shafiq and Shakeel, 2010), Ibuprofen (Sharma et al., 2011), Indomethacin (Obitte et al., 2014), Paclitaxel (Cho et al., 2016), and Carvedilol (Ibrahim et al., 2018).

Table (1): Biopharmaceutical Classification System (BCS) classes

\begin{tabular}{|c|c|c|c|c|}
\hline $\begin{array}{c}\text { BCS } \\
\text { classes }\end{array}$ & $\begin{array}{c}\text { Aqueous } \\
\text { solubility }\end{array}$ & $\begin{array}{c}\text { Membrane } \\
\text { permeability }\end{array}$ & $\begin{array}{c}\text { Absorption } \\
\text { pattern }\end{array}$ & Problems overcome by SEDDS \\
\hline Class I & High & High & Well absorbed & $\begin{array}{c}\text { Enzymatic degradation and gut wall } \\
\text { efflux }\end{array}$ \\
\hline Class II & Low & High & Well absorbed & Solubilization and bioavailability \\
\hline $\begin{array}{c}\text { Class } \\
\text { III }\end{array}$ & High & Low & Variable & $\begin{array}{c}\text { Enzymatic degradation, gut wall } \\
\text { efflux and bioavailability }\end{array}$ \\
\hline $\begin{array}{c}\text { Class } \\
\text { IV }\end{array}$ & Low & Low & $\begin{array}{c}\text { Poorly } \\
\text { absorbed }\end{array}$ & $\begin{array}{c}\text { Solubilization, enzymatic degradation, } \\
\text { gut wall efflux and bioavailability }\end{array}$ \\
\hline
\end{tabular}

\section{Oils}

The oil represents one of the most important excipients in the SEDDS formulation. Not only because it can solubilize marked amounts of the lipophilic drug or facilitate self-emulsification, but also it can increase the fraction of the lipophilic drug transported via the intestinal lymphatic system, thereby increasing the absorption of drug from the GIT. It also influences the SE ability of the formulation and drug precipitation in GIT (Cerpnjak et al., 2013).

Examples of oils that may be used in the preparation of SEDDS are represented in Table (2). Long-chain triglycerides (natural edible oils) are not frequently preferred in SEDDS formulation owing to their poor ability to dissolve large amounts of lipophilic drugs. While, medium-chain mixed glycerides have become popular excipients having even greater solvent capacity and enhanced ability to promote emulsification and lack of susceptibility to oxidation (Porter et al., 2004).

\section{Surfactants}

In the context of oral lipid-based formulations, the surfactant is obligatory to provide the essential emulsifying characteristics to SEDDS. Surfactants of intermediate hydrophilic-lipophilic balance (HLB) (8-12) which adsorb strongly at oilwater $(\mathrm{O} / \mathrm{W})$ interfaces are called 'water insoluble surfactants'. These materials are insufficiently hydrophilic to dissolve in water and form micelles, but nevertheless are sufficiently hydrophilic to be capable of driving self-emulsification. These surfactants are sometimes described as 'dispersible' in water, meaning that they can form an emulsion if subject to shear. These materials typically are predominantly oleate esters such as Tween 85 (Zhang et al., 2015).

The most commonly used surfactants for formulation of SEDDS are 'water soluble 
Zagazig J. Pharm. Sci. June, 2018

Vol. 27, Issue 1, pp. 1- 21

surfactants' as shown in Table (2). Above their critical micelle concentration, these materials dissolve in pure water at low concentrations to form micellar solutions. They imply HLB values of approximately 12 or greater (Pouton and Porter, 2008).

The role of surfactants in SEDDS formulation is to reduce the interfacial tension and adjust the spontaneous curvature of the interface. This enables the dispersion process and provides the formation of a flexible film that can easily cover the lipid core of the emulsion droplets. This film can lead to spontaneous formation of a microemulsion (Figure 2) (Müllertz et al., 2010).

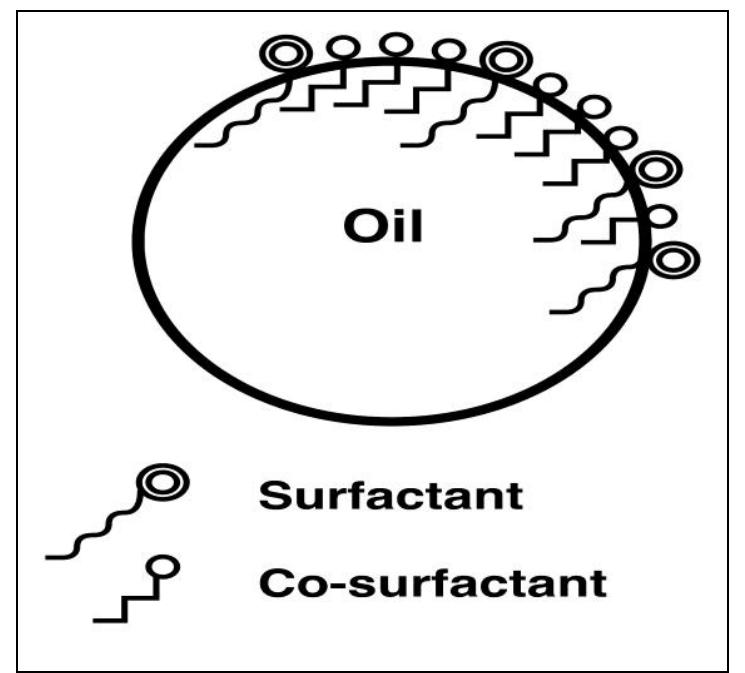

Figure (2): Composition of SEDDS

Safety is a major determining factor in choosing a surfactant. Non-ionic surfactants are often used in pharmaceutical applications and SEDDS formulations because of their lower toxicity. They have greater stability towards the changes in the ionic strength and $\mathrm{pH}$ that are likely to be encountered in the biological environment (Zhang et al., 2015).

Usually the surfactant concentration ranges between 30 and $60 \% \mathrm{w} / \mathrm{w}$ in order to form stable SEDDS. It is very important to determine the surfactant concentration properly because large amounts of surfactants may lead to reversible changes in
ISSN 1110-5089

ISSN (on-line) 2356_9786

the permeability of the intestinal lumen (Gursoy and Benita, 2004).

\section{Co-surfactants}

It has been assumed that co-surfactants can be included to improve the solubility of the drug in SEDDS and increase the solvent capacity of the formulation for drugs which dissolve freely in the co-surfactants. To enhance the solvent capacity, the cosurfactant must be presented at high concentration (generally more than 30\% $\mathrm{w} / \mathrm{w})$. This may constitute a problem since the polar co-surfactant will partition into the aqueous phase and reduce the solubilization capacity of the dispersed system resulting in precipitation of the drug compound (Pouton and Porter, 2008; Müllertz et al., 2010). Examples of commonly used co-surfactants are represented in Table (2).

5. Polymers

Inert polymers representing from 5 to $40 \% \mathrm{w} / \mathrm{w}$ of the composition are capable of forming a matrix used in the formulation of sustained release SEDDS preparations (Barthelemy and Benameur, 2001). Gao et al., 2003 developed a new supersaturable SEDDS of Paclitaxel by using hydroxyl propylmethyl cellulose (HPMC) polymer as a precipitation inhibitor. In another study, Wei et al. 2012 reported that rapid precipitation of silybin drug from SEDDS formulation without HPMC was noticed resulting in low drug concentration in the GI fluids.

\section{Overview of SEDDS formation and phase behavior}

\section{Theory of SEDSS formation}

According to Reiss, 1975, selfemulsification occurs when the entropy change that favors dispersion is greater than the energy required to increase the surface area of the dispersion. The free energy of the conventional emulsion can express the formation of new surface between the oil and water phases. This can be described by the following equation: 
Zagazig J. Pharm. Sci. June, 2018

Vol. 27, Issue 1, pp. 1- 21

\section{$\mathrm{DG}=\Sigma \mathrm{N} \pi \mathbf{r} \mathbf{2 \sigma}$}

Where, DG: the free energy associated with the process (ignoring the free energy of mixing), $\mathbf{N}$ : the number of droplets of radius (r) and $\boldsymbol{\sigma}$ : the interfacial energy.

\section{Phase behavior}

The relationship between the phase behavior of a mixture and its composition can be determined by using the phase diagram. The phase behavior of simple microemulsion systems comprising oil, water and surfactant can be studied using ternary phase diagram in which each corner of the
ISSN 1110-5089

ISSN (on-line) 2356_9786

diagram represents $100 \%$ of that particular component. The diagram helps to determine the optimum concentration ranges of different excipients necessary to obtain SEDDS.

More commonly, when the microemulsion contains additional components such as a co-surfactant, pseudoternary phase diagrams are used where one corner typically represents a binary mixture of two components such as surfactantcosurfactant mixture (Figure 3) (Lawrence and Rees, 2012).

Table (2): Components of SEDDS

\begin{tabular}{|c|c|c|c|}
\hline Component & Examples & Drug & References \\
\hline \multirow{12}{*}{ Oils } & \multicolumn{3}{|c|}{ Long-chain triglycerides such as: } \\
\hline & Soyabean oil & Cyclosporine & (Odeberg et al., 2003) \\
\hline & Castor oil & Ibuprofen & (Sharma et al., 2011) \\
\hline & Sesame oil & Leflunomide & (El-Sayyad et al., 2017) \\
\hline & \multicolumn{3}{|c|}{ Medium-chain triglyceride oils such as: } \\
\hline & $\begin{array}{l}\text { fractionated coconut } \\
\text { and palm seed oils }\end{array}$ & Cyclosporine & (Odeberg et al., 2003) \\
\hline & Miglyol $^{\circledR}$ & Bifendate & (Yanyu et al., 2013) \\
\hline & Captex $^{\circledR}$ & Atorvastatin & $\begin{array}{c}\text { (Czajkowska-Kośnik et al., } \\
\text { 2015) }\end{array}$ \\
\hline & \multicolumn{3}{|c|}{ Medium-chain mixed glycerides such as: } \\
\hline & Maisine $^{\circledR}$ & Glibenclamide & (Nawale and Mehta, 2013) \\
\hline & Peceol $^{\circledR}$ & Lutein & (Yoo et al., 2013) \\
\hline & Capryol $^{\circledR}$ & Rosuvastatin calcium & (Kulkarni et al., 2015) \\
\hline \multirow{3}{*}{ Surfactants } & Tween 20 & Celecoxib & (Chavan et al., 2015) \\
\hline & Cremophore $^{\circledR}$ & Carbamazepine & (Milović et al., 2012) \\
\hline & Labrasol $^{\circledR}$ & Lercanidipine $\mathrm{HCl}$ & (Kallakunta et al., 2013) \\
\hline \multirow{4}{*}{$\begin{array}{c}\text { Co- } \\
\text { surfactants }\end{array}$} & Polyethylene glycol & Curcumin & (Cui et al., 2009) \\
\hline & Ethanol & Ketoprofen & (Nawale et al., 2015) \\
\hline & Propylene glycol & Resveratrol & (Balata et al., 2016) \\
\hline & Transcutol $^{\circledR}$ & Carvedilol & (Ibrahim et al., 2018) \\
\hline
\end{tabular}




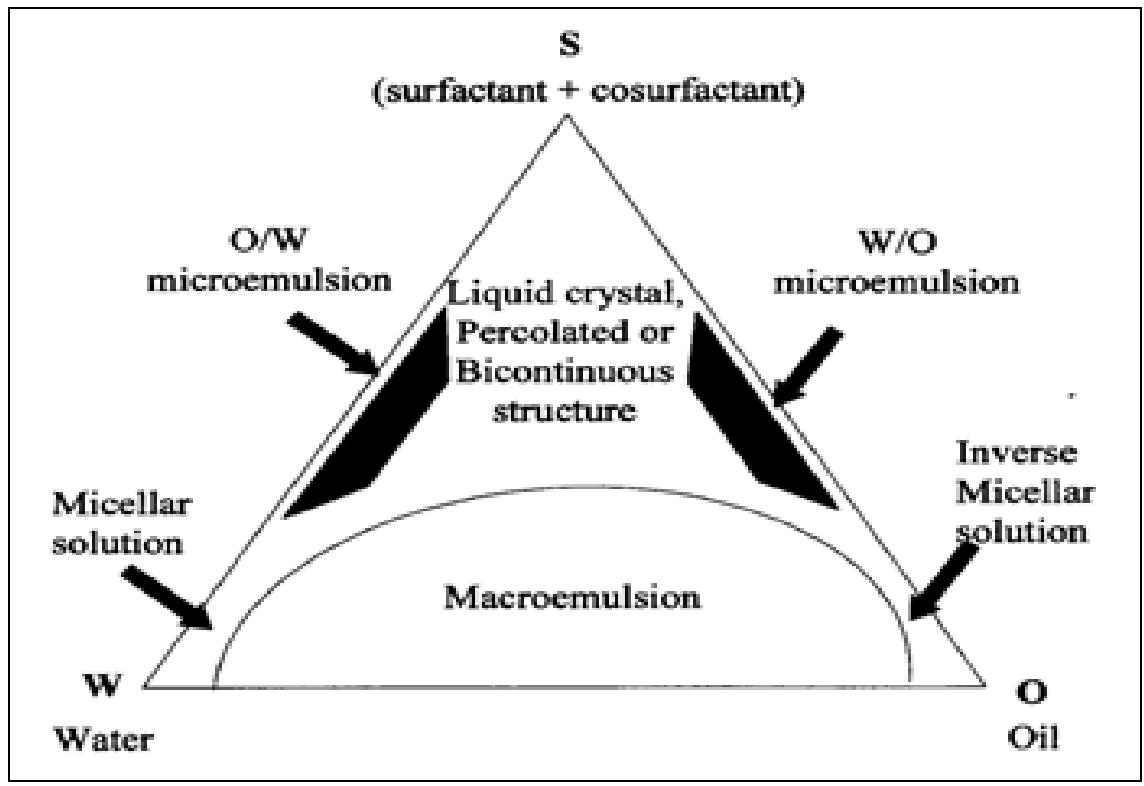

Figure (3): Pseudo-ternary phase diagram (Patel et al., 2014a)

\section{Factors affecting SEDDS}

\section{Dose of drug}

Drugs which are administered at very high dose are not suitable for SEDDS, unless they exhibit extremely good solubility in at least one of the components of SEDDS (preferably the lipophilic phase). Drugs which exhibit limited solubility in water and lipids and posses low $\log \mathrm{P}$ value of approximately 2, are most difficult to be delivered by SEDDS (Pouton, 2000; Chime et al., 2014).

\section{The risk of precipitation}

The solubility of the drug in oil phase greatly influences the ability of SEDDS in maintaining the drug in solution state. When the drug is solubilized by the use of surfactant or co-surfactant, the dilution of SEDDS formulation with water can lead to lowering the solvent capacity of surfactant or co-surfactant. This may result in precipitation of the drug. This depends on the $\log \mathrm{P}$ of the drug and to what extent the surfactant is contributing to drug solubilization within the formulation (Pouton, 2000; Chime et al., 2014).

\section{Emulsion droplet polarity}

The emulsion droplet polarity is one of the most important factors in characterizing the emulsification efficiency. Hydrophiliclipophilic balance, chain length, degree of unsaturation of the fatty acid, molecular weight of the hydrophilic portion and concentration of the surfactant have an impact on polarity of the oil droplet. The polarity reflects the affinity of the drug for oil and/or water and the type of forces involved. The high polarity will enhance the drug release into the aqueous phase (Gursoy and Benita, 2004). This is confirmed by Kim et al., 2000 who observed that the release rate of Idebenone from SEDDS was dependent on the polarity of the oil phase used. The highest release was obtained with formulations that had highly polar oily phase. Physicochemical characterization of SEDDS

\section{Percent transmittance}

The primary means of self-emulsification assessment is visual evaluation. To avoid any subjective variations, the percent transparency obtained on dilution/reconstitution of the SE formulations is measured using Ultravioletvisible (UV-VIS) spectrophotometer at $\lambda_{\max }$ ranged between 630-650 nm (Gupta et al., 2013). 
Zagazig J. Pharm. Sci. June, 2018

Vol. 27, Issue 1, pp. 1- 21

\section{Droplet size}

The droplet size of the emulsion is a crucial factor in self-emulsification performance because it determines the rate and extent of the drug release and absorption. It has been reported that the droplet size distribution is one of the most important characteristics of the in-vivo fate of drug emulsion. The globule size is most commonly measured based on the principle of dynamic light scattering (DLS) or photon correlation spectroscopy (PCS) (Yang et al., 2004).

\section{Robustness to dilution}

Robustness to dilution is the ability of the emulsion formed to maintain similar properties at different degrees of dilutions in order to achieve uniform drug release profile. Also, it is important to ensure that the drug will not get precipitated at higher dilutions in-vivo which may significantly retard the absorption of the drug from the formulation (Gupta et al., 2013).

\section{Zeta potential}

Zeta potential is used to identify the surface charge of the oil droplets which is usually negative due to the presence of free fatty acids (Creţu and Şolea, 2017). Generally, zeta potential helps to predict the stability and flocculation effect in the emulsion systems where a high zeta potential value (more than $\pm 30 \mathrm{mV}$ ) maintains a stable system. If the zeta potential falls below this level, the colloid will aggregate due to the attractive forces (Kosnik et al., 2015).

\section{Determination of self-emulsification time}

The rate of self-emulsification is usually determined by adding a dose of the SEDDS (preferably in a capsule) to an amount of water or biorelevant media. By visual observation or by monitoring the change of turbidity in emulsion using a UV-VIS spectrophotometer, the rate of emulsification is determined (Müllertz et al., 2010). The mechanism of emulsification involves the erosion of a fine cloud of small particles
ISSN 1110-5089

ISSN (on-line) 2356_9786

from the surface of large droplets, rather than a progressive reduction in droplet size (Kohli et al., 2010).

\section{Thermodynamic stability studies}

The physical stability of the lipid-based formulation is also crucial to its performance which can be adversely affected by precipitation of the drug in the excipient mixture. In addition, poor physical stability can lead to phase separation of the excipients affecting not only the formulation performance, but the visual appearance as well. The three following cycles have been used to examine the stability of the selected SEDDS formulations (Subramanian and Siddalingam, 2017):

a) Heating and cooling cycles: Six cycles of cooling and heating between refrigerator temperature $\left(4^{\circ} \mathrm{C}\right)$ and elevated temperature $\left(45^{\circ} \mathrm{C}\right)$ with exposure at each temperature for not less than $48 \mathrm{hr}$ can be carried out. The formulations, which were stable, were then subjected to centrifugation test.

b) Centrifugation: Formulations that passed the heating and cooling cycles were centrifuged at $15000 \mathrm{rpm}$ for 15 min. Those formulations that did not show any phase separation were taken for the freezing and thawing test.

c) Freezing and thawing cycles: Three freezing and thawing cycles between freezing temperature $\left(-18^{\circ} \mathrm{C}\right)$ and room temperature $\left(25^{\circ} \mathrm{C}\right)$ with storage at each temperature for not less than $48 \mathrm{hr}$ can be performed. Those formulations that passed this test, showed good stability with no phase separation, cracking or creaming.

\section{In-vitro dissolution studies}

In-vitro dissolution studies are carried out to study the drug release behavior and to predict the in-vitro assessment of bioavailability. USP dissolution apparatus type II using simulated gastric fluid $(\mathrm{pH} 1.2)$ maintained at a temperature of $37 \pm 0.5^{\circ} \mathrm{C}$ is usually used (Khedekar and Mittal, 2013). 
Zagazig J. Pharm. Sci. June, 2018

Vol. 27, Issue 1, pp. 1- 21

To improve the accuracy of in-vivo dissolution, several studies have developed and defined modified dissolution media that more accurately reflect the solubilization power of the in-vivo GI tract. Although solubility of poorly water-soluble compounds in the stomach is not sufficient for appreciable dissolution before gastric emptying, the stomach is the principal site of dissolution. Hence, simulated gastric fluid can be used to simulate gastric conditions (Kohli et al., 2010). Dressman and Reppas, 2000 have compared the dissolution profiles of several poorly water-soluble compounds using different dissolution media.

\section{Solidification techniques for transforming liquid or semisolid SEDDS to solid SEDDS}

Solid SEDDS technology is a novel particle technology that provides an effective alternative strategy to the conventional liquid SEDDS for formulating drugs with poor aqueous solubility (Abdalla and Mäder, 2007). These solid SEDDS formulations are prepared by the incorporation of liquid or semisolid SE ingredients into powders or nanoparticles by different solidification techniques such as:

\section{Capsule filling}

Capsule filling is the simplest and the most common technology for the encapsulation of liquid or semisolid SE formulations for the oral route (Gupta et al., 2013).

For semisolid formulations, it is a four-step process:

- Heating of the semisolid excipient to $20^{\circ} \mathrm{C}$ (at least) above its melting point.

- Incorporation of the active drug substances with stirring.

- Filling of the molten mixture in capsules.

- Cooling to room temperature $\left(25^{\circ} \mathrm{C}\right)$.

For liquid formulations, it involves two-step process:
ISSN 1110-5089

ISSN (on-line) 2356_9786

- Filling of the formulation into the capsules.

- Sealing of the body and cap of the capsule, either by banding (depositing a gelatin band) or by microspray sealing.

A primary consideration in capsule filling is the compatibility of the excipients with the capsule shell. The advantages of capsule filling method are simplicity of manufacturing; suitability for low-dose highly potent drugs and high drug loading (up to $50 \% \mathrm{w} / \mathrm{w}$ ) (Jannin et al., 2008).

2. Spray drying

Essentially, spray drying technique involves the preparation of the formulation ingredients such as drug, lipids, surfactants and solid carriers. The solubilized liquid formulation is then atomized into a spray of droplets. The droplets are introduced into a drying chamber where the volatile phase (e.g. the water contained in an emulsion) evaporates forming dry particles under controlled temperature and airflow conditions. Such particles can be further prepared into tablets or capsules. The atomizer temperature, airflow pattern and drying chamber design are selected according to the drying characteristics of the product and powder specification (Yi et al., 2008). Oh et al., 2011 focused on the effect of different types of solid carriers such as dextran and colloidal silica on the formulation of solid SEDDS of flurbiprofen using spray drying technique.

\section{Adsorption to solid carriers}

Free flowing powders may be obtained from liquid lipid formulations by adsorption techniques. The adsorption process is simple and involves addition of the liquid formulation onto the carrier of choice by mixing in a blender. The carriers used for this purpose include microporous calcium silicate $\quad\left(\right.$ Florite $\left.^{\circledR} \quad \mathrm{RE}\right)$, magnesium alminometa silicate $\left(\right.$ Neusilin $\left.{ }^{\circledR} \quad \mathrm{US}_{2}\right)$ or 
Zagazig J. Pharm. Sci. June, 2018

Vol. 27, Issue 1, pp. 1- 21

silicon dioxide (Sylysia ${ }^{\circledR}$ 320) (Ito et al., 2005; Ahuja and Pathak, 2007).

The carriers should be selected for their ability to adsorb a great quantity of liquid excipients achieving high drug loading, high lipid exposure and good flowability of the mixture after adsorption. The resulting free flowing powder may then be filled directly into capsules or alternatively mixed with suitable excipients before compression into tablets (Shrestha et al., 2014). A significant benefit of the adsorption technique is the good content uniformity and the possibility for high lipid exposure of SEDDS (up to $70 \% \mathrm{w} / \mathrm{w}$ ) adsorbed onto suitable carriers (Jannin et al., 2008).

An alternative method of solid SEDDS preparation was adopted by Agarwal et al., 2013 in their study. Where, the powdered SE lipid formulation of meloxicam was obtained by simple trituration of liquid SEDDS with a solid adsorbent (mixture of silicon dioxide and magnesium aluminum silicate 1:1) until a homogenous blend was formed. The powdered SEDDS formulation showed higher bioavailability in beagle dogs when compared with that of commercially available tablets. In another study, solid SEDDS of fenofibrate was formulated by solidification of the molten solution of the oily phase, surfactant, co-surfactant and drug mixture with PEG 6000 polymer. Where, the solid SEDDS formulation with $10 \% \mathrm{w} / \mathrm{w}$ fenofibrate loading showed as much as 20fold increase in the dissolution profile (Kanaujia et al., 2014).

On the other hand, Kang et al., 2011 pointed out that strong adsorption and physical interaction of the drug with the carriers may cause retarded or incomplete release of the drug from the solid SEDDS formulations.

\section{Melt granulation}

Melt granulation or pelletization is a single step-process that allows the transformation of the powder mixture containing the SE liquid drug into granules
ISSN 1110-5089

ISSN (on-line) 2356_9786

or spheronized pellets. This technique necessitates a high shear mixing with a presence of a meltable binder which may be sprayed in molten state onto the powder mixture. The melted binder forms liquid bridges with the powder particles which can be shaped into small agglomerates and transformed to spheronized pellets (Shrestha et al., 2014). The main parameters that control the granulation process are the impeller speed, mixing time, binder particle size and viscosity of the binder (Seo and Schæfer, 2001).

A wide range of solid and semisolid lipids can be applied as meltable binders such as Gelucire ${ }^{\circledR}$ that is able to increase the dissolution rate of drugs owing to its SE property (Seo et al., 2003). Also, the melt granulation process may be used for adsorbing SE systems on solid neutral carriers such as Neusilin ${ }^{\circledR} \mathrm{US}_{2}$ (Gupta et al., 2002).

5. Melt extrusion/extrusion spheronization

Extrusion is a process of converting the raw material with plastic properties into a product of uniform shape and density. This can be achieved by forcing it through a die under controlled temperature, product flow and pressure conditions. Melt extrusion is a solvent-free process that allows high drug loading as well as content uniformity (Breitenbach, 2002; Jannin et al., 2008). The extrusion-spheronization process requires the following steps (Newton et al., 2001):

- Mixing of the active SE drug and excipients to achieve a homogeneous powder.

- Wet massing with a binder.

- Extrusion into a spaghetti-like extrudate.

- Spheronization from the extrudate to uniform size spheroids.

Serratoni et al., 2007 prepared SE controlled release pellets by incorporating methyl and propyl parabens into a SE system 
Zagazig J. Pharm. Sci. June, 2018

Vol. 27, Issue 1, pp. 1- 21

followed by coating the pellets by extrusion/spheronization method. In addition, SE pellets of progesterone and bilayered cohesive SE pellets have been prepared by Tuleu et al., 2004; Iosio et al., 2008.

\section{Various dosage forms of SEDDS}

\section{Dry emulsions}

Dry emulsions are powdery, lipid-based formulations from which an $\mathrm{O} / \mathrm{W}$ emulsion can easily be reconstituted when exposed to an aqueous solution and thus they present a potential for drug delivery system (Gallarate et al., 2009). From a pharmaceutical point of view, dry emulsions are attractive due to their physical strength and ease of administration as capsules (Hansen et al., 2005) and tablets (Salama et al., 2018). They are generally prepared by drying liquid $\mathrm{O} / \mathrm{W}$ emulsions containing a soluble or an insoluble solid carrier in an aqueous medium. Afterwards, the aqueous phase is removed causing the solid carrier to encapsulate the dispersed lipid phase. Lactose, maltodextrin (Calvo et al., 2010), sucrose (Monica and Shital, 2014), gelatin (Bertoldo et al., 2016), mannitol (Niczinger et al., 2017), etc are examples of solid carriers that are more commonly used. Also, insoluble carriers like colloidal silica can be used (Sucheta et al., 2012).

Dry emulsions have a spongy powder appearance and can be considered as an actual emulsion being constituted of a hydrophilic phase which is eliminated by rotary evaporation (Myers and Shively, 1992), freeze drying (Choi et al., 2007) or spray drying (Monica and Shital, 2014).

2. Self-emulsifying capsules

After oral administration of the conventional liquid SE formulations in form of capsules, microemulsion droplets are formed and subsequently disperse in the GI tract to reach the sites of absorption. However, if the irreversible phase separation of the microemulsion occurs, an improvement of drug absorption cannot be
ISSN 1110-5089

ISSN (on-line) 2356_9786

expected (Itoh et al., 2002). The SEDDS can be designed using a small quantity of polymers such as HPMC in the formulation to prevent precipitation of the drug by generating and maintaining a supersaturated state in-vivo. This system contains a reduced amount of surfactant, thereby minimizing the GI side effects (Gao et al., 2003).

Ansari et al., 2014 developed an efficient and convenient SE system of felodipine where the SEDDS formulations were filled in hard gelatin capsules due to their anhydrous nature enabling the administration of the drug as unit dosage form. The hard gelatin capsules were coated with a polymer in order to achieve a rapid drug release after a desired time lag in the management of hypertension. In another study, to enhance the solubility and permeability of hydrochlorothiazide via SEDDS, the SEDDS formulation was transformed into a free flowing powder and non-effervescent floating capsules containing solid SEDDS of the drug were prepared (Jagdale and Phargade, 2017). In addition, oral administration of SE capsules solidified using different kinds of adsorbents has been found to enhance patient compliance compared with the parenteral route (Ito et al., 2006).

3. Self-emulsifying sustained/controlled release tablets

The SE tablets consist of solidified liquid SEDDS either compressed or molded into tablets. These preparations offer many advantages because these tablets can liquify at body temperature under agitation due to the peristaltic movement of GIT that will lower the liquification time, resulting in faster emulsification with increased drug plasma concentration (Wagh et al., 2014).

In order to reduce the amount of solidifying excipients required for transformation of SEDDS into solid dosage forms, a gelled SEDDS has been developed. Where, Carbopol (Zhang et al., 2002) and Aerosil 200 (Patil et al., 2004) were selected 
Zagazig J. Pharm. Sci. June, 2018

Vol. 27, Issue 1, pp. 1- 21

as gelling agents which helped in slowing down of the drug release. Patil et al., 2016 prepared orodispersible sustained release tablets of domperidone which were useful for paediatric and geriatric patients or patients having disrupts in swallowing ability or dysphagia.

The newest advance in the research field of SE tablets is the SE osmotic pump tablets. Where, the elementary osmotic pump system was chosen as the carrier of SEDDS. This system has outstanding features such as stable plasma concentrations, controlled release rate and enhanced bioavailability of drugs (Wei et al., 2007; Shriniwas et al., 2014).

4. Self-emulsifying sustained/controlled release pellets

Although the application of SEDDS is primarily intended for improvement of the absorption of poorly water soluble drugs, it would also be desirable to provide sustained release action in the case of drugs having short biological half-life with low and frequent dosing. For this reason, the combinations of SEDDS with control release agents have been studied in order to develop a matrix type controlled release solid SEDDS. Matrix type spherical pellets of solid SEDDS have been developed offering the benefits of both absorption improvement and sustained release (Zhang et al., 2012). Thus, it is very appealing to combine the advantages of pellets with those of SEDDS by SE pellets.

Self-emulsifying (SE) pellets as multiple unit dosage forms can be filled easily into capsules or processed into tablets. Due to the spherical shape, smooth surface and narrow size distribution of pellets, SE pellets are particularly suitable for sustained release formulations. These formulations are prepared either by application of a sustained release coating from a polymeric dispersion or solution onto the drug containing pellets, or by employing mixtures of pellets forming powder excipients such as microcrystalline
ISSN 1110-5089

ISSN (on-line) 2356_9786

cellulose (MCC) with sustain release agents to form a sustained release matrix (Nikolakakis and Partheniadis, 2017). These excipients are usually gel-forming hydrophilic polymers such as cellulose ethers like HPMC (Liu et la., 2017) and methacrylic acid based polymers like carbopol or colloidal silicon dioxide (Podczeck, 2008).

Experiments with colloidal silicon dioxide in mixtures with MCC using SEDDS added as emulsions-binders in extrusion/spheronization process showed that good quality pellets can be formed. Therefore, colloidal silicon dioxide serves a multi-purpose; as a pellet forming powder, a strong adsorbent and gelling agent that provides a controlled release of drugs (Patel et al., 2014b; Agrawal et al., 2015).

5. Self-emulsifying solid dispersions

Self-emulsifying solid dispersions are efficient techniques that successfully improve the solubility and oral bioavailability of many lipophilic drugs with classical polymers or solubilizers (Ansari et al., 2016). Preparation of SE solid dispersions is an economic way to improve wettability, increase surface area, reduce agglomeration and convert the drug to its amorphous state leading to higher rate of solvation (Craig, 2002). Melting method and solvent method are the major conventional techniques employed to prepare SE solid dispersions (Eloy and Marchetti, 2014). Where, the melting method involves the melting and rapid cooling of the drug-polymer mixture to obtain the supersaturation. The solvent method involves the solubilization of the drug and carrier in a common volatile solvent system followed by evaporation.

The key to the success for the previous methods is the conversion of drug to its amorphous form which enjoys higher solubility. Since the amorphous drug in the solid dispersions is thermodynamically unstable and can recrystallize during storage 
Zagazig J. Pharm. Sci. June, 2018

Vol. 27, Issue 1, pp. 1- 21

leading to decrease in the solubility, it can hinder the benefits of the amorphous approach (Shah et al., 2012). Hence, polymer carriers in SE solid dispersion preparations can be used to retard recrystallization and improve stability of the amorphous drug. Highly water soluble semicrystalline polymers including gelucires ${ }^{\circledR}$ and poloxamers ${ }^{\circledR}$ are commonly used in the preparation of SE solid dispersions. Swain and Subudhi, 2018 studied the crystallization behavior of nateglinide in SE solid dispersions and the influence of these polymers on stability of its amorphous state in order to improve its solubility and oral bioavailability.

6. Self-emulsifying beads

It was hypothesized that using capillary forces SEDDS can be developed to transform the SE formulation into a solid form with minimum amounts of solidifying aids and avoid leaking and leaching problems of conventional liquid SE formulations. These capillary forces SEDDS can be loaded into the microchannels of preformed porous polystyrene beads (PPB) typically produced by copolymerizing styrene and divinyl benzene (Patil and Paradkar, 2006). Porous polystyrene beads (PPB) are inert and stable over a wide $\mathrm{pH}$ range and extreme conditions of temperature and humidity. They consist of hydrocarbon backbone with benzene rings and are devoid of any functional groups (Rigby et al., 2004). Porous polystyrene beads have also been used as controlled release carriers for liquid biocides that are added before copolymerization (Patil and Paradkar, 2006).

7. Self-emulsifying sustained-release microspheres

In order to design a sustained-release formulation of an oily drug, the sustainedrelease microspheres with SE capability has been prepared. You et al. 2006 developed sustained-release microspheres containing zedoary turmeric oil by the emulsion-
ISSN 1110-5089

ISSN (on-line) 2356_9786

solvent-diffusion method of the spherical crystallization technique in order to improve the bioavailability of the drug. In another study, Li and Yi, 2013 prepared SE microspheres by membrane emulsification technology with the solid carrier in a gel state formed by sodium alginate and calcium chloride.

8. Self-emulsifying suppositories

Rectal administration is often sought as an alternative route of administration to overcome the gastric irritation, nausea and vomiting that may be associated with oral administration. Furthermore, drugs are administered rectally to achieve ease and safety of administration when the oral route is not convenient as in infants and elderly patients (Cetinkaya, 2012).

Kim and Ku, 2000 examined the SEDDS as a potential vehicle for enhancing the absorption of indomethacin where the SEDDS formulation containing the drug was administered orally or rectally to rats. Where, the area under the curve $\left(\mathrm{AUC}_{0-12 \mathrm{hr}}\right)$ increased significantly ( $41 \%$ increase) after rectal administration of gelatin hollow type suppositories filled with SEDDS containing indomethacin to rats. Also, Gugulothu et al., 2010 developed SE suppositories of $\beta$ artemether as an alternative dosage form to overcome the gastric irritation, nausea, and vomiting that may be associated with oral administration.

9. Self-emulsifying ocular delivery systems

Ocular drugs are usually formulated as eye drops in solutions or suspensions. The major problem in ocular therapy is low topical absorption of drugs caused by relative impermeability of cornea and short residence time of the ocular preparation. This problem may result from precorneal events such as tear turnover, tear dilution or blinking. The drug bioavailability from eye drops is typically less than $5 \%$. On the other hand, recommended frequent dosing at high concentration can result in several side 
Zagazig J. Pharm. Sci. June, 2018

Vol. 27, Issue 1, pp. 1- 21

effects and decreased patient compliance (Gaudana et al., 2009).

For ophthalmic administration, dilutable nanoemulsions are potent drug delivery because of their numerous advantages such as sustained effect and high ability of drug penetration into the deeper layers of the
ISSN 1110-5089

ISSN (on-line) 2356_9786

ocular structure and the aqueous humor (Lallemand et al., 2012). Mangiafico et al., 2011 developed a new self-emulsified, transparent and stable nanosystem for delivering lipophilic topical ocular drugs such as betamethasone dipropionate, latanoprost and cyclosporine A.

\section{Marketed preparations of SEDDS}

Table (3): Marketed preparations of SEDDS (Hauss, 2007; Savla et al., 2017)

\begin{tabular}{|c|c|c|c|c|c|}
\hline No. & Drug & Trade name & Company & Type of formulation & Indication \\
\hline \multirow{2}{*}{1} & Cyclosporin & Sandimmune $^{(\circledR)}$ & \multirow{2}{*}{ Novartis } & Oral solution & \multirow{2}{*}{$\begin{array}{l}\text { Immuno- } \\
\text { suppressant }\end{array}$} \\
\hline & & Neoral $^{\circledR}$ & & Soft gelatin capsule & \\
\hline 2 & Sirolimus & Rapamune $^{\circledR}$ & $\begin{array}{l}\text { Wyeth- } \\
\text { Ayerst }\end{array}$ & Oral solution & $\begin{array}{c}\text { Immuno- } \\
\text { suppressant }\end{array}$ \\
\hline 3 & Tipranavir & Aptivus $^{\circledR}$ & $\begin{array}{l}\text { Boehringer } \\
\text { Ingelheim }\end{array}$ & Soft gelatin capsule & HIV antiviral \\
\hline 4 & Ritonavir & Novir $^{(\circledR)}$ & Abbott & Soft gelatin capsule & HIV antiviral \\
\hline 5 & Isotretinoin & Accutane $^{\circledR}$ & Roche & Hard gelatin capsule & $\begin{array}{l}\text { Treatment of } \\
\text { nodular acne }\end{array}$ \\
\hline
\end{tabular}

\section{CONCLUSION}

From the present review, SEDDS have been shown to substantially improve the solubility, dissolution and oral bioavailability of poorly water soluble drugs. With future development of this technology, SEDDS will continue to enable novel applications in drug delivery and solve problems associated with the delivery of hydrophobic drugs. As alternatives of conventional liquid SEDDS, solid SEDDS are superior in reducing the production cost, simplifying the industrial manufacture and improving the stability and patient compliance. Moreover, solid SEDDS are very flexible to formulate various solid dosage forms with different routes of administration and controlled/sustained release of drugs.

\section{CONFLICT OF INTEREST}

The authors report no conflicts of interest.

\section{REFERENCES}

Abdalla A. and Mäder K. (2007) "Preparation and characterization of a self-emulsifying pellet formulation", European Journal of Pharmaceutics and Biopharmaceutics; 66 (2): 220-226.

Agarwal V., Alayoubi A., Siddiqui A. and Nazzal S. (2013) "Powdered self-emulsified lipid formulations of meloxicam as solid dosage forms for oral administration", Drug Development and Industrial Pharmacy; 39 (11): 1681-1689.

Agrawal A.G., Kumar A. and Gide P.S. (2015) "Self emulsifying drug delivery system for enhanced solubility and dissolution of glipizide", Colloids and Surfaces B: Biointerfaces; 126: 553-560.

Ahuja G. and Pathak K. (2007) "Porous carriers for controlled/modulated drug delivery", Indian Journal of Pharmaceutical Sciences; 71 (6): 599-607.

Ansari K.A. , Pagar K.P., Anwar S. and Vavia P.R. (2014) "Design and optimization of self-microemulsifying drug delivery system (SMEDDS) of felodipine for 
Zagazig J. Pharm. Sci. June, 2018

Vol. 27, Issue 1, pp. 1- 21

chronotherapeutic application", Brazilian Journal of Pharmaceutical Sciences; 50 (1): 203-212.

Ansari M.T., Arshad M.S., Hussain A. and Ahmad Z. (2016) "Improvement of solubility, dissolution and stability profile of artemether solid dispersions and self emulsified solid dispersions by solvent evaporation method", Pharmaceutical development and technology; 1-9.

Balata G.F., Essa E.A., Shamardl H.A., Zaidan S.H. and Abourehab M.A.S. (2016) "Self-emulsifying drug delivery systems as a tool to improve solubility and bioavailability of resveratrol", Drug Design, Development and Therapy; 10: 117-128.

Barthelemy P. and Benameur H. (2001) "Composition with sustained release of active principle, capable of forming a microemulsion", US patent 0004459 A1.

Bertoldo M., Coltelli M., Messina T., Bronco S. and Castelvetro V. (2016) "An emulsion blending approach for the preparation of Gelatin/Poly(butylene succinate-co-adipate) films", ACS Biomaterials Science \& Engineering; 2 (4): 677-686.

Bodade S.S, Shaikh K.S., Kamble M.S. and Chaudhari P.D. (2013) "A study on ethosomes as mode for transdermal delivery of an antidiabetic drug", Drug Delivery; 20 (1): 40-46.

Breitenbach J. (2002), "Melt extrusion: from process to drug delivery technology", European Journal of Pharmaceutics and Biopharmaceutics; 54 (22): 107-117.

Bulbake U., Doppalapudi S., Kommineni N. and Khan W. (2017) "Liposomal formulations in clinical use: An updated review", Pharmaceutics; 9 (12): 1-33.

Calvo P., Hernandez T., Lozano M. and Gonzalez-Gomez D. (2010) "Microencapsulation of extra-virgin olive oil by spray-drying: Influence of wall material and olive quality", European Journal of Lipid Science and Technology; 112 (8): 852858.
ISSN 1110-5089

ISSN (on-line) 2356_9786

Cerpnjak K., Zvonar A., Gasperlin M. and Vrecer F. (2013) "Lipid-based systems as a promising approach for enhancing the bioavailability of poorly water-soluble drugs", Acta Pharmaceutica; 63 (4): 427445.

Cetinkaya S. (2012) "Administration and dose of the most frequently used drugs in paediatrics", InTech; Chapter 16: 298.

Chavan R.B., Modi S.R. and Bansal A.K. (2015) "Role of solid carriers in pharmaceutical performance of solid supersaturable SEDDS of celecoxib", International Journal of Pharmaceutics; 495 (1): 374-284.

Chime S.A., Kenechukwu F.C. and Attama A.A (2014) "Nanoemulsions - Advances in formulation, characterization and applications in drug delivery", Application of Nanotechnology in Drug Delivery; Chapter 3: 77-126.

Cho H., Kang J., Ngo L., Tran P. and Lee Y. (2016) "Preparation and evaluation of solidself-emulsifying drug delivery system containing paclitaxel for lymphatic delivery", Journal of Nanomaterials: 1-14.

Choi M.J., Briancon S., Bazile D., Royere A., Min S.G. and Fessi H. (2007) "Effect of cryoprotectant and freeze-drying process on the stability of w/o/w emulsions", Drying Technology; 25 (5): 809-819.

Craig D.Q. (2002) "The mechanisms of drug release from solid dispersions in watersoluble polymers", International Journal of Pharmceutics; 231 (2): 131-144.

Crețu R. and Şolea L.C. (2017) "Zeta potential and color investigations of vegetable oil based emulsions as ecofriendly lubricants", Scientific Study \& Research: Chemistry \& Chemical Engineering, Biotechnology, Food Industry; 18 (2): 167-180.

Cui J., Yu B., Zhao Y., Zhu W., Li H., Lou H. and Zhai G. (2009) "Enhancement of oral absorption of curcumin by selfmicroemulsifying drug delivery systems", 
Zagazig J. Pharm. Sci. June, 2018

Vol. 27, Issue 1, pp. 1- 21

International Journal of Pharmaceutics; 371 (1-2): 148-155.

Czajkowska-Kośnik A., Szekalska M., Amelian A., Emilia Szymańska E. and Winnicka K. (2015) "Development and evaluation of liquid and solid selfemulsifying drug delivery systems for atorvastatin", Molecules; 20 (12): 21010 21022.

Dressman J.B. and Reppas C. (2000) "In vitro-in vivo correlations for lipophilic, poorly water-soluble drugs", European Journal of Pharmaceutical Sciences; 11 (Suppl. 2): S73-S80.

Eloy J.O. and Marchetti J.M. (2014) "Solid dispersions containing ursolic acid in poloxamer 407 and PEG 6000: a comparative study of fusion and solvent methods", Powder Technology; 253: 98-106.

El-Sayyad N.M.E., Badawi A., Abdullah M.E. and Abdelmalak N.S. (2017) "Dissolution enhancement of leflunomide incorporating self emulsifying drug delivery systems and liquisolid concepts", Bulletin of Faculty of Pharmacy, Cairo University; 55 (1): 53-62.

Gallarate M., Mittone E., Carlotti M.E., Trotta M. and Piccerelle P. (2009) "Formulation of Dry Emulsion for Topical Applications", Journal of Dispersion Science and Technology; 30 (6): 823-833.

Gao P., Rush B.D., Pfund W.P., Huang T., Bauer J.M., Morozowich W., Kuo M.S. and Hageman M.J. (2003) "Development of a supersaturable SEDDS (S-SEDDS) formulation of paclitaxel with improved oral bioavailability", Journal of Pharmaceutical Sciences; 92 (12): 2386-2398.

Gaudana R., Jwala J., Boddu S.H.S. and Mitra A.K. (2009) "Recent perspectives in ocular drug delivery", Pharmaceutical Research, Vol. 26 (5): 1197-1216.

Gershanik T., Haltner E., Lehr C.M. and Benita S. (2000) "Charge-dependent interaction of self-emulsifying oil formulations with Caco- 2 cells monolayers: binding, effects on barrier function and
ISSN 1110-5089

ISSN (on-line) 2356_9786

cytotoxicity", International Journal of Pharmaceutics; 211 (1): 29-36.

Gugulothu D., Pathak S., Suryavanshi S., Sharma S. and Patravale V. (2010) "Selfmicroemulsifiyng suppository formulation of $\beta$-artemether", American Association of Pharmaceutical Scientists PharmSciTech; 11 (3): 1179-1184.

Gupta M.K., Tseng Y.C., Goldman D. and Bogner R.H. (2002) "Hydrogen bonding with adsorbent during storage governs drug dissolution from solid-dispersion granules", Pharmaceutical Research; 19 (11): 16631672.

Gupta S., Kesarla R., Omri A. (2013) "Formulation strategies to improve the bioavailability of poorly absorbed drugs with special emphasis on self-emulsifying systems", International Scholarly Research Notices; 1-16.

Gursoy R.N. and Benita S. (2004) "Selfemulsifying drug delivery systems (SEDDS) for improved oral delivery of lipophilic drugs", Biomedicine and Pharmacotherapy; 58 (3): 173-182.

Hansen T., Holm P., Rohde M. and Schultz K. (2005) "In vivo evaluation of tablets and capsules containing spray-dried o/wemulsions for oral delivery of poorly soluble drugs", International Journal of Pharmaceutics; 293 (1-2): 203-211.

Hauss D.J. (2007) "Oral lipid-based formulations: enhancing the bioavailability of poorly water soluble drugs", Informa Healthcare, New York; 170: 1-61.

Holm R., Porter C.J.H., Edwards G.A., Mullertz A., Kristensen H.G. and Charman W.N. (2003) "Examination of oral absorption and lymphatic transport of halofantrine in a triple-cannulated canine model after administration in selfmicroemulsifying drug delivery systems (SMEDDS) containing structured triglycerides", European Journal of Pharmaceutical Sciences; 20 (1): 91-97.

Ibrahim T.M., Abdallah M.H., El-Megrab N.A. and El-Nahas H.M. (2018) 
Zagazig J. Pharm. Sci. June, 2018

Vol. 27, Issue 1, pp. 1- 21

"Upgrading of dissolution and antihypertensive effect of Carvedilol via two combined approaches: self-emulsification and liquisolid techniques", Drug Development and Industrial Pharmacy; 44 (6): 873-885.

Iosio T., Voinovich D., Grassi M., Pinto J.F., Perissutti B., Zacchigna M., Quintavalle U. and Serdoz F. (2008) "Bi-layered selfemulsifying pellets prepared by co-extrusion and spheronization: Influence of formulation variables and preliminary study on the in vivo absorption", European Journal of Pharmaceutics and Biopharmaceutics; 69 (2): 686-697.

Ito Y., Kusawake T., Ishida M., Tawa R., Shibata N. and Takada K. (2005) "Oral solid gentamicin preparation using emulsifier and adsorbent", Journal of Controlled Release; 105 (1): 23-31.

Ito Y., Kusawake T., Prasad Y.V.R., Sugioka N., Shibata N.and Takada K. (2006) "Preparation and evaluation of oral solid heparin using emulsifier and adsorbent for in vitro and in vivo studies", International journal of pharmaceutics; 317 (2): 114-119.

Itoh K., Tozuka Y., Oguchi T. and Yamamoto K. (2002) "Improvement of physicochemical properties of $\mathrm{N}-4472$ part I formulation design by using selfmicroemulsifying system", International journal of pharmaceutics; 238 (1-2): 153160.

Jagdale S. and Phargade P. (2017) "Development and optimization of floating capsule for solid self microemulsified drug delivery of hydrochlorothiazide", Current Drug Therapy; 12.

Jannin V., Musakhanian J. and Marchaud D. (2008) "Approaches for the development of solid and semi-solid lipid-based formulations", Advanced Drug Delivery Reviews; 60 (6): 734-746.

Kallakunta V.R., Eedara B.B., Jukanti R., Ajmeera R.K. and Bandari S. (2013) "A Gelucire 44/14 and labrasol based solid self emulsifying drug delivery system:
ISSN 1110-5089

ISSN (on-line) 2356_9786

formulation and evaluation", Journal of Pharmaceutical Investigation; 43 (3): 185196.

Kanaujia P., Ng W.K. and Tan R.B.H. (2014)

"Solid self-emulsifying drug delivery system (S-SEDDS) for improved dissolution rate of fenofibrate", Journal of microencapsulation; 31 (3): 293-298.

Kang M.J., Jung S.Y., Song W.H., Park J.S., Choi S., Oh K.T., Choi H., Choi Y.W., Lee J., Lee B. and Chi S. (2011) "Immediate release of ibuprofen from Fujicalin ${ }^{\circledR}$-based fast-dissolving self-emulsifying tablets ",Drug Development and Industrial Pharmacy; 37(11): 1298-1305.

Kaukonen A.M., Boyd B.J., Porter C.J.H. and Charman W.N. (2004) "Drug solubilization behavior during in vitro digestion of simple triglyceride lipid solution formulations", Pharmaceutical Research; 21 (2): 245-253.

Kawabata Y., Wadab K., Nakatanib M., Yamadaa S. and Onouea S. (2011) "Formulation design for poorly watersoluble drugs based on biopharmaceutics classification system: Basic approaches and practical applications", International Journal of Pharmaceutics; 420 (1): 1-10.

Khedekar K. and Mittal S. (2013) "Self emulsifying drug delivery system: a review", International Journal of Pharmaceutical Sciences and Research; 4 (12): 4494-4507.

Kim H.J., Yoon K.A., Hahn M., Park E.S. and Chi S.C. (2000) "Preparation and in vitro evaluation of self-microemulsifying drug delivery systems containing Idebenone", Drug Development and Industrial Pharmacy; 26 (5): 523-529.

Kim J.Y. and Ku Y.S. (2000) "Enhanced absorption of indomethacin after oral or rectal administration of a self-emulsifying system containing indomethacin to rats", International Journal of Pharmaceutics; 194 (1): 81-89.

Kohli K., Chopra S., Dhar D., Arora S and Khar R.K. (2010) "Self-emulsifying drug delivery systems: an approach to enhance 
Zagazig J. Pharm. Sci. June, 2018

Vol. 27, Issue 1, pp. 1- 21

oral bioavailability", Drug Discovery Today; 15 (21): 958-965.

Kommuru T.R., Gurley B., Khan M.A. and Reddy I.K. (2001) "Self-emulsifying drug delivery systems (SEDDS) of coenzyme Q10: formulation development and bioavailability assessment", International Journal of Pharmaceutics; 212 (2): 233-246.

Kosnik A.C., Szekalska M., Amelian A., Szymanska E. and Winnicka K. (2015) "Development and evaluation of liquid and solid self-emulsifying drug delivery systems for atorvastatin", Molecules; 20 (12): 2101021022.

Kulkarni N.S., Ranpise N.S. and Mohan G. (2015) "Development and evaluation of solid self nano-emulsifying formulation of rosuvastatin calcium for improved bioavailability", Tropical Journal of Pharmaceutical Research; 14 (4): 575-582.

Lallemand F., Daull P., Benita S., Buggage R. and Garrigue J. (2012) "Successfully improving ocular drug delivery using the cationic nanoemulsion, novasorb", Journal of Drug Delivery, 2012: 1-16.

Lawrence M.J. and Rees G.D. (2012) "Microemulsion-based media as novel drug delivery systems", Advanced Drug Delivery Reviews; 64: 175-193.

Li H. and Yi T. (2013) "Preparation and in vitro characterization of berberine hydrochloride - $\quad$ Self-emulsifying microsphere by membrane emulsification technology", Acta pharmaceutica Sinica; 48 (4):554-559.

Liu M., Zhang S., Cui S., Chen F., Jia L., Wang S., Gai X., Li P., Yang F., Pan W. and Yang $X$. (2017) "Preparation and evaluation of Vinpocetine self-emulsifying $\mathrm{pH}$ gradient release pellets", Drug Delivery, 24 (1): 1598-1604.

Mangiafico S., Aleo D., Saita M.G., Vinciguerra R., Cro M.G. and Mangiafico S. (2011) "A new ophthalmic selfemulsifying nanosystem to deliver lipophilic drugs", Investigative Ophthalmology and Visual Science; 52 (14): 450-460.
ISSN 1110-5089

ISSN (on-line) 2356_9786

Milović M., Djuriš J., Djekić L., Vasiljević D. and Ibrić S. (2012) "Characterization and evaluation of solid self-microemulsifying drug delivery systems with porous carriers as systems for improved carbamazepine release", International Journal of Pharmaceutics; 436 (1-2): 58-65.

Monica R.R.P. and Shital S.A. (2014) "Spraydried redispersible emulsion to improve oral bioavailability of itraconazole", Journal of Surfactants and Detergents; 17 (4): 807-817.

Müllertz A., Ogbonna A., Ren S. and Rades T. (2010) "New perspectives on lipid and surfactant based drug delivery systems for oral delivery of poorly soluble drugs", Journal of Pharmacy and Pharmacology; 62 (11): 1622-1636.

Myers S.L. and Shively M.L. (1992) "Preparation and characterization of emulsifiable glasses: oil-in-water and waterin-oil-in-water emulsion", Journal of colloid and interface science; 149 (1): 271-278.

Nawale R.B. and Mehta B.N. (2013) "Glibenclamide loaded selfmicroemulsifying drug delivery system (smedds): Development and optimization", International Journal of Pharmacy and Pharmaceutical Sciences; 5 (2), 325-330.

Nawale R.B., Salunke P.B. and Jadhav A.B. (2015) "Ketoprofen loaded solid self emulsifying drug delivery system (SEDDS): Development and optimization", International Journal of Pharmaceutical Sciences Review and Research; 33 (1): 102108.

Newton M., Petersson J., Podczeck F., Clarke A. and Booth S. (2001) "The influence of formulation variables on the properties of pellets containing a selfemulsifying mixture", Journal of Pharmaceutical Sciences; 90 (8): 987-995.

Niczinger N.A., Kállai-Szabó B., Lengyel M., Gordon P., Klebovich I. and Antal I. (2017) "Physicochemical analysis in the evaluation of reconstituted dry emulsion tablets", Journal of pharmaceutical and biomedical analysis; 134: 86-93. 
Zagazig J. Pharm. Sci. June, 2018

Vol. 27, Issue 1, pp. 1- 21

Nielsen F.S., Petersen K.B. and Mullertz A. (2008) "Bioavailability of probucol from lipid and surfactant based formulations in minipigs: Influence of droplet size and dietary state", European Journal of Pharmaceutics and Biopharmaceutics; 69: 553-562.

Nikolakakis I. and Partheniadis I. (2017) "Self-emulsifying granules and pellets: Composition and formation mechanisms for instant or controlled release", Pharmaceutics; 9 (4): 50-77.

Obitte N.C., Ofokansi K.C. and Kenechukwu F.C. (2014) "Development and evaluation of novel self-nanoemulsifying drug delivery systems based on a homolipid from capra hircus and its admixtures with melon oil for the delivery of indomethacin", Journal of Pharmaceutics; 2014: 1-9.

Odeberg J.M., Kaufmann P., Kroon K.G. and Höglund P. (2003) "Lipid drug delivery and rational formulation design for lipophilic drugs with low oral bioavailability, applied to cyclosporine", European Journal of Pharmaceutical Sciences; 20 (4): 375-382.

Oh D.H., Kang J.H., Kim D.W., Lee B.J., Kim J.O., Yong C.S. and Choi H.G. (2011) "Comparison of solid selfmicroemulsifying drug delivery system (solid SMEDDS) prepared with hydrophilic and hydrophobic solid carrier", International Journal of Pharmaceutics; 420 (2): 412-418.

Okur N.U., Caglar E.S., Arpa M.D. and Karasulu H.Y. (2017) "Preparation and evaluation of novel microemulsion-based hydrogels for dermal delivery of benzocaine", Pharmaceutical Development and Technology; 22 (4): 500-510.

Patel R.R., Patel K.R. and Patel M.R. (2014a) "Formulation and characterization of microemulsion based gel of antifungal drug", PharmaTutor; 2 (2): 79-89.

Patel J., Dhingani A., Tilala J., Mihir R. and Sheth N. (2014b) "Formulation and development of self-nanoemulsifying granules of olmesartan medoxomil for
ISSN 1110-5089

ISSN (on-line) 2356_9786

bioavailability enhancement", Particulate Science and Technology; 32 (3): 274-290.

Patil H.G., Tiwari R.V., Repka M.A. and Singh K.K. (2016) "Formulation and development of orodispersible sustained release tablet of domperidone", Drug development and industrial pharmacy; 42 (6): 906-915.

Patil P. and Paradkar A. (2006) "Porous polystyrene beads as carriers for selfemulsifying system containing loratadine", American Association of Pharmaceutical Scientists PharmSciTech; 7 (1): E1-E7.

Patil P., Joshi P. and Paradkar A. (2004) "effect of formulation variables on preparation and evaluation of gelled selfemulsifying drug delivery system (SEDDS) of ketoprofen", American Association of Pharmaceutical Scientists PharmSciTech; 5 (3): 1-8.

Podczeck F. (2008) "A novel aid for the preparation of pellets by extrusion/spheronization pellets", Pharmaceutical Technology Europe; 20 (12): 26-31.

Porter C.J.H. and Charman W.N. (2001) "In vitro assessment of oral lipid based formulations", Advanced Drug Delivery Reviews; 50: S127-S147.

Porter C.J.H., Kaukonen A.M., Boyd B.J., Edwards G.A. and Charman W.N. (2004) "Susceptibility to lipase-mediated digestion reduces the oral bioavailability of danazol after administration as a medium-chain lipidbased microemulsion formulation", Pharmaceutical Research; 21 (8): 14051412.

Porter C.J.H., Pouton C.W., Cuine J.F. and Charman W.N. (2008) "Enhancing intestinal drug solubilisation using lipidbased delivery systems", Advanced Drug Delivery Reviews; 60 (6): 673-691.

Pouton C.W. (2000) "Lipid formulations for oral administration of drugs: non emulsifying, self-emulsifying and 'selfmicroemulsifying' drug delivery systems", 
Zagazig J. Pharm. Sci. June, 2018

Vol. 27, Issue 1, pp. 1- 21

European Journal of Pharmaceutical Sciences; 11 (2): S93-S98.

Pouton C.W. and Porter C.J.H. (2008) "Formulation of lipid-based delivery systems for oral administration: Materials, methods and strategies", Advanced Drug Delivery Reviews; 60 (6): 625-637.

Ravalika V. and Sailaja A.K. (2017) "Formulation and evaluation of etoricoxib niosomes by thin film hydration technique and ether injection method", Nano Biomedicine and Engineering; 9 (3): 242248.

Reiss H. (1975) "Entropy-induced dispersion of bulk liquids", Journal of Colloid and Interface Science; 53 (1): 61-70.

Rigby S.P., Fletcher R.S. and Riley S.N. (2004) "Characterization of porous solids using integrated nitrogen sorption and mercury porosimetry", Chemical Engineering Science; 59 (1): 41-51.

Salama A.H., Basha M. and El Awdan S. (2018) "Experimentally designed lyophilized dry emulsion tablets for enhancing the antihyperlipidemic activity of atorvastatin calcium: preparation, in-vitro evaluation and in-vivo assessment", European Journal of Pharmaceutical Sciences; 112: 52-62.

Savla R., Browne J., Plassat V., Wasan K.M. and Wasan E.K. (2017) "Review and analysis of FDA approved drugs using lipidbased formulations", Drug Development and Industrial Pharmacy; 43 (11): 1743-1758.

Seo A. and Schæfer T. (2001) "Melt agglomeration with polyethylene glycol beads at a low impeller speed in a high shear mixer", European Journal of Pharmaceutics and Biopharmaceutics; 52 (3): 315-325.

Seo A., Holm P. and Kristensen H.G. (2003) "The preparation of agglomerates containing solid dispersions of diazepam by melt agglomeration in a high shear mixer", International Journal of Pharmaceutics; 259 (1-2): 161-171.

Serratoni M., Newton M., Booth S. and Clarke A. (2007) "Controlled drug release from pellets containing water-insoluble
ISSN 1110-5089

ISSN (on-line) 2356_9786

drugs dissolved in a self-emulsifying system", European Journal of Pharmaceutics and Biopharmaceutics; 65 (1): 94-98.

Shafiq S. and Shakeel F. (2010) "Stability and self-nanoemulsification efficiency of ramipril nanoemulsion containing labrasol and plurol oleique", Clinical Research and Regulatory Affairs; 27 (1): 7-12.

Shah N., Sandhu H., Choi D.S., Kalb O., Page S. and Wyttenbach N. (2012) "Structured development approach for amorphous systems", New York: Springer: 267-310.

Sharma S., Sharma A.D., Naseer M.D.A. and Singh R. (2011) "Formulation and evaluation of self emulsifying drug delivery system of ibuprofen using castor oil", International Journal of Pharmacy and Pharmaceutical Sciences; 3 (4): 299-302.

Shrestha H., Bala R. and Arora S. (2014) "Lipid-Based Drug Delivery Systems", Journal of Pharmaceutics, 2014: 1-10.

Shriniwas Y., Sumit P., Pankaj S. and Anurag B. (2014) "Design and development of solid self micro-emulsifying osmotic drug delivery system for isradipine", Journal of Drug Delivery and Therapeutics; 28-41.

Stella B., Peira E., Dianzani C., Gallarate M., Battaglia L., Gigliotti C.L., Boggio E., Dianzani U. and Dosio F. (2018) "Development and characterization of solid lipid nanoparticles loaded with a highly active doxorubicin derivative", Nanomaterials; 8 (2): 1-16.

Subramanian P. and Siddalingam R. (2017) "Self-nanoemulsifying drug delivery systems of poorly soluble drug dutasteride: Formulation and in-vitro characterization", Journal of Applied Pharmaceutical Science; 7 (4): 11-22.

Sucheta B., Komal S., Kiran J., Mithun P. and Rajendra P. (2012) "Solubility enhancement of antihypertensive drug by dry emulsion technique", Novel Science International Journal of Pharmaceutical Science; 1 (7): 493-496. 
Zagazig J. Pharm. Sci. June, 2018

Vol. 27, Issue 1, pp. 1- 21

Swain R.P. and Subudhi B.B. (2018) "Effect of semicrystalline polymers on selfemulsifying solid dispersions of nateglinide: in vitro and in vivo evaluation", Drug Development And Industrial Pharmacy; 44 (1): 56-65.

Tuleu C., Newton M., Rose J., Euler D., Saklatvala R., Clarke A. and Boot S. (2004) "Comparative bioavailability study in dogs of a self-emulsifying formulation of progesterone presented in a pellet and liquid form compared with an aqueous suspension of progesterone", Journal of pharmaceutical sciences; 93 (6): 1495-1502.

Wagh M.P., Singh P.K., Chaudhari C.S. and Khairnar D.A. (2014) "Solid selfemulsifying drug delivery system: preparation techniques and dosage forms", International Journal of Biopharmaceutics; 5 (2): 101-108.

Wei L., Li J., Guo L., Nie S., Pan W., Sun P. and Liu H. (2007) "Investigations of a novel self-emulsifying osmotic pump tablet containing carvedilol", Drug Development and Industrial Pharmacy; 33 (9): 990-998.

Wei Y.W., Ye X., Shang X., Peng X., Bao Q., Liu M., Guo M. and Li F., (2012) "Enhanced oral bioavailability of silybin by a supersaturatable self-emulsifying drug delivery system (S-SEDDS)", Colloids and Surfaces A: Physicochemical and Engineering Aspects; 396: 22-28.

Yang S., Gursoy R.N., Lambert G. and Benita S. (2004) "Enhanced oral absorption of paclitaxel in a novel self microemulsifying drug delivery system with or without concomitant use of Pglycoprotein inhibitors", Pharmaceutical Research; 21 (2): 261-270.

Yanyu X., Shan W., Yinan C. and Qineng P. (2013) "Self-emulsifying bifendate pellets:
ISSN 1110-5089

ISSN (on-line) 2356_9786

preparation, characterization and oral bioavailability in rats", Drug Development and Industrial Pharmacy; 39 (5): 724-732.

Yi T., Wan J., Xu H. and Yang X. (2008) “A new solid self-microemulsifying formulation prepared by spray-drying to improve the oral bioavailability of poorly water soluble drugs", European Journal of Pharmaceutics and Biopharmaceutics; 70 (2): 439-444.

Yoo J., Baskaran R. and Yoo B. (2013) "Selfnanoemulsifying drug delivery system of lutein: physicochemical properties and effect on bioavailability of warfarin", Biomolecules and Therapeutics; 21 (2): 173179.

You J., Cui F., Han X., Wang Y., Yang L., Yu Y. and Li Q. (2006) "Study of the preparation of sustained-release microspheres containing zedoary turmeric oil by the emulsion-solvent-diffusion method and evaluation of the selfemulsification and bioavailability of the oil", Colloids and Surfaces B: Biointerfaces; 48 (1): 35-41.

Zhang L., Zhang L., Zhang M., Pang y., Li Z., Zhao A. and Feng J. (2015) "Selfemulsifying drug delivery system and the applications in herbal drugs", Drug Delivery; 22(4): 475-486.

Zhang Y., Wang R., Wu J. and Shen Q. (2012) "Characterization and evaluation of self-microemulsifying sustained-release pellet formulation of puerarin for oral delivery", International journal of pharmaceutics; 427 (2): 337-344.

Zhang Y., Zhang J.S., Chen G.G, Zhang F. and Wang M. (2002) "Development of verapamil hydrochloride self-emulsifying sustained-release tablets and exploration of released character", Journal-China Pharmaceutical University; 33 (3): 208-210. 


$$
\text { طارق ابر اهيم ، مروة عبدالله ، ناجية المجر ابلاب ، الناقلة للعقار النحاس }
$$

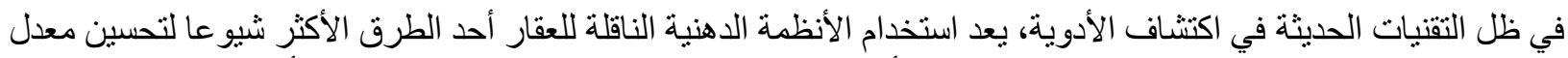

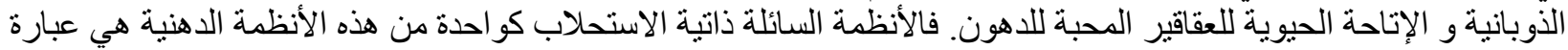

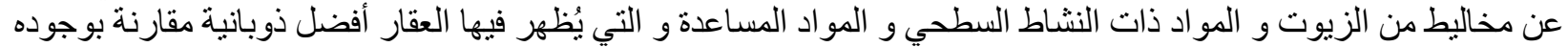

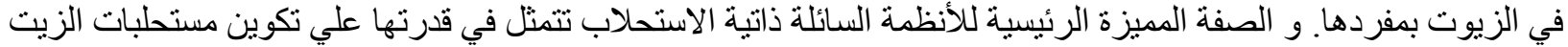

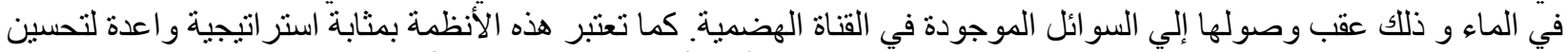

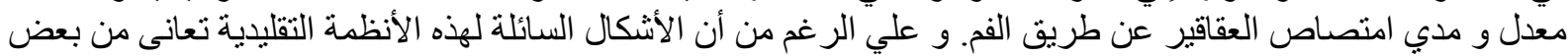

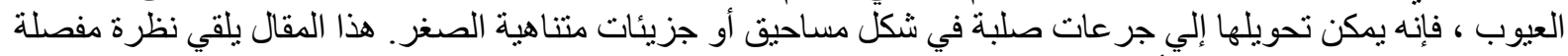

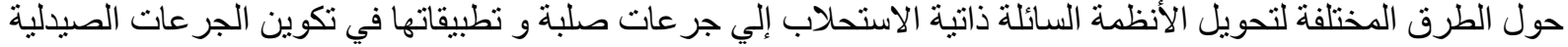

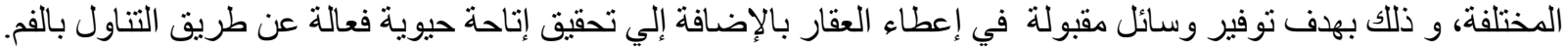

